\title{
A ÉTICA NA COMUNICAÇÃO CIENTÍFICA: DA INVESTIGAÇÃO À PUBLICAÇÃO
}

\author{
ETHICS IN SCIENTIFIC COMMUNICATION: FROM RESEARCH TO PUBLICATION
}

\author{
Mario Angelo Cenedesi Júnior ${ }^{1}$ \\ Elessandro Ferreira Dutra ${ }^{2}$ \\ Francirlúcya Silva Colares ${ }^{3}$ \\ Sandra Helena Brito Rodrigues ${ }^{4}$ \\ Willian Paschoalim de Mello ${ }^{5}$ \\ Silvia Elena Vouillat ${ }^{6}$
}

RESUMO: A Comunicação Científica é a troca de informações entre membros que compoem uma Comunidade Científica, sendo de importante para a produção científica, divulgando informações. Conhecer sobre Ética e seus passos são de suma importância para a criação de uma pesquisa sólida, coesa, que gerará resultados confiáveis que, por sua vez, poderão ser apresentados através de uma comunicação efetiva. O presente trabalho traz uma análise sobre Ética e sua importância na pesquisa, desde o começo da investigação até a apresentação dos dados, através de uma comunicação científica eficaz e correta.

Palavras-chave: Comunicação científica. Investigação. Ética em pesquisa.

ABSTRACT: Scientific communication is the exchange of information between members that make up a Scientific Community, being important for scientific production, disseminating information. Knowing about Ethics and its steps are of paramount importance for the creation of solid, cohesive research, which will generate reliable results that, in turn, can be presented through effective communication. This work presents an analysis of Ethics and its importance in research, from the beginning of the investigation to the presentation of data, through effective and correct scientific communication.

\footnotetext{
I Doutorando em Saúde Pública pela Universidad de Ciencias Empresariales y Sociales (UCES), Buenos Aires-Argentina. https://orcid.org/oooo-ooor-844I-8321. E-mail: mariocenedesi@outlook.com.

${ }^{2}$ Doutorando em Saúde Pública pela Universidad de Ciencias Empresariales y Sociales (UCES), Buenos Aires-Argentina; pós-graduado em Ultrassonografia Geral pela UniEVANGELICA, Anápolis-GO.

${ }_{3}^{3}$ Doutoranda em Saúde Pública pela Universidad de Ciencias Empresariales y Sociales (UCES), Buenos Aires-Argentina.

4 Doutoranda em Saúde Pública pela Universidad de Ciencias Empresariales y Sociales (UCES), Buenos Aires-Argentina.

${ }^{5}$ Doutorando em Saúde Pública pela Universidad de Ciencias Empresariales y Sociales (UCES), Buenos Aires-Argentina.

6 Professora-doutora da Universidad de Ciencias Empresariales y Sociales (UCES), Buenos AiresArgentina; doutora em Saúde Pública, com menção em Sistemas e Serviços de Saúde, pela Universidad de Ciencias Empresariales y Sociales (UCES), Buenos Aires-Argentina
} 
Keywords: Scientific communication. Investigation. Research ethics.

\section{INTRODUÇÃO}

A comunicação científica (CC) é definida como a troca de informação entre os membros que compõem a Comunidade Científica, sendo também considerada como uma atividade associada à produção científica, com o objetivo de divulgar informação, desde o momento em que surge a ideia até o momento da divulgação dos resultados da pesquisa. A literatura científica e a CC são elementos importantes para se fazer Ciência, bem como para a divulgação do conhecimento científico.

Como afirma Meadows (1999), a comunicação científica “[...] está no cerne da ciência. Para ela, é tão vital quanto a própria investigação". Considera-se que uma publicação científica que siga preceitos éticos proporcione credibilidade e maiores chances de ser aprovada pela comunidade científica. Ou seja, além de ser reconhecida e aludida, também traz prestígio ao autor, além de permitir o financiamento de projetos de pesquisa a ele associados.

O nascimento da CC formal tem como marco os encontros de pesquisadores 'faculdades invisíveis' - promovidos regularmente desde a década de 1640, e patrocinados pela Royal Society of London, com o intuito de divulgar experiências, apresentar artigos e divulgar os resultados das pesquisas. (Meadows, 1999). A troca de informações ocorrida nestas reuniões foi complementada com a troca de correspondência, que permitiu a quem não teve oportunidade de assistir pessoalmente às reuniões, que também participou no debate. Com o aumento do número de cartas trocadas, a revista científica apareceu como um meio eficaz de divulgação de informações em maior escala. As primeiras revistas científicas - Journal des Sçavans (Paris), editado por Dennis de Sallo, e Philosophical Transactions of Royal Society of London, com Henry Oldenburg como o primeiro editor ambas iniciadas em 1665 - foram publicadas por sociedades científicas.

O Journal des Sçavans é creditado com a primazia do "jornal moderno nas humanidades”, devido ao seu caráter polissêmico em relação ao assunto que publicou (Meadows, 1999), enquanto dois assuntos predominaram em Philosophical Transactions, um político e outro religiosos, e a ênfase estava em estudos experimentais. Inicialmente, os periódicos 
científicos cobriam o acervo de cartas trocadas entre pesquisadores, constituindo também um arquivo dos resultados e observações feitas durante os experimentos realizados.

Naturalmente, esse tipo de publicação estava associado à função de registrar a "titularidade" da descoberta científica e apresentar as informações em arquivo indexado (Scahduer, 1994). Também denotou agilidade na comunicação dos resultados da pesquisa, formalizando o processo de comunicação, tanto como modelo para o registro da propriedade intelectual quanto como modelo para a preservação do conhecimento. Vários autores consideram que o periódico científico tem a função de constituir uma memória da ciência e um meio de divulgação dos resultados da pesquisa para a comunidade de pesquisadores e acadêmicos, bem como para a sociedade em geral (Vickery, 200o). Atualmente, continua a ser o meio reconhecido e legítimo de divulgação da CC, embora os livros continuem a ser, em muitas áreas do conhecimento, um importante meio de divulgação (Gomes, 2013).

A eficácia do CC é fundamental na formação dos futuros profissionais, bem como fundamental para a qualidade da clínica do profissional capacitado. A pesquisa científica não é um segmento específico da academia, deve fazer parte do cotidiano do profissional, que pode embasar suas práticas e sua importância, tanto para seus pacientes quanto para os demais profissionais, com base em evidências científicas. Para uma atuação adequada do profissional clínico moderno, é imprescindível saber analisar a qualidade dos estudos na literatura, mesmo que não exerçam atividades como pesquisador, precisando ser crítico e entender quais são as descobertas clinicamente relevantes (Vickery, 200o).

A relevância da CC é reforçada pela constatação de que, além de simplesmente divulgar os resultados das pesquisas, ela é publicada de forma ética. Essa ética não está relacionada apenas à moral individual ou mesmo a um código de ética profissional, mas, sobretudo, a uma "ciência do comportamento", o que nos leva a refletir sobre o impacto que o conhecimento científico produz na sociedade contemporânea (Abbagnano, 2007). Aqui, a questão não é apenas a ética aplicada aos profissionais da informação, mas, também, a ética da informação, onde questões de privacidade, sigilo, segurança, acesso e autoria tornam-se fundamentais para a compreensão da informação como fenômeno. 
Assim, conhecer as bases da escrita do CC é de extrema importância para a construção de um trabalho sólido, coeso, de qualidade, ético e que contribua para a disseminação do conhecimento (neste caso, o objeto do trabalho a ser comunicado).

\section{DESENVOLVIMENTO: A COMUNICAÇÃO CIENTÍFICA, EM SI}

O cientista da comunicação Herbert Menzel, em 1958, definiu CC como: "[... ] a totalidade de publicações, recursos, oportunidades, sistemas institucionais e costumes que afetam a transmissão direta ou indireta de mensagens científicas entre cientistas". (Gomes, 2013) Este autor sintetiza as funções do CC, destacando seu papel no desenvolvimento da ciência e na atuação dos cientistas:

a) fornecer respostas a perguntas específicas;

b) contribuir para a atualização profissional do cientista na área específica de sua atuação;

c) estimular a descoberta e compreensão de novos campos de interesse;

d) divulgar tendências em áreas emergentes, dando aos cientistas uma ideia da relevância do seu trabalho;

e) testar a confiabilidade de novos conhecimentos, dada a possibilidade de testemunhos e verificações;

f) redirecionar ou ampliar a lista de interesses científicos;

g) fornecer feedback para melhorar a produção do cientista.

Vickery (200o) (e apoiado por outros autores, o que se demonstra, a seguir) corrobora afirmando que o desenvolvimento do CC pode ser delineado, em seis grandes períodos:

(I) Civilizações antigas (por volta de $600 \mathrm{aC}$ ) e cultura clássica (6oo aC a $500 \mathrm{dC}$ ): não se trata apenas da criação do alfabeto. Os gregos antigos foram os responsáveis pela cultura letrada do pensamento moderno. A revolução ocorreu não apenas por meio da palavra escrita, mas, também, em discussões e reuniões realizadas fora de Atenas para debater questões filosóficas (Meadows, 1999). Os gregos são atribuídos às atividades que dão origem ao CC, ou seja, à troca de ideias entre pares, característica desse sistema de comunicação. As obras de Aristóteles, por exemplo, tiveram um grande impacto, tanto na cultura árabe quanto na Europa Ocidental. As ideias contidas nesses manuscritos 
contribuíram para reviver o conhecimento entre os séculos i4 e i6, período conhecido como Renascimento. Esses manuscritos foram registrados em diferentes suportes inicialmente em papiro, pergaminho e finalmente em papel - a oralidade não podia mais propagar o volume de informações, era necessário o registro;

(2) O período medieval (500-I450): o surgimento das universidades na Europa na Idade Média, foi fundamental para a transmissão do conhecimento e ocorreu a partir dos ensinamentos da Igreja e como resultado do Renascimento intelectual que se originou no século XI em torno da Teologia e Filosofia. A tarefa dos professores era expor as posições de autoridades reconhecidas, como Aristóteles, Hipócrates, Tomás de Aquino, entre outras. Foi neste contexto das universidades e, posteriormente, das sociedades científicas do século XVII, que surgiram os fenômenos que influenciaram a consolidação de uma sociedade de leitura e a institucionalização da Ciência. Para Le Goff (2003), os cursos universitários contribuíram para a evolução do leitor medieval da leitura em voz alta para a leitura visual e silenciosa. O livro universitário está relacionado a um contexto técnico, social e econômico totalmente novo. A revolução na técnica do livro, ocorrida no século XV-XVI, é fruto do trabalho desenvolvido na "oficina universitária". Tal contribuição será decisiva para a tradição editorial universitária, que tem nas editoras de Cambridge e Oxford, nascidas na Idade Média, exemplos de atuação até os dias de hoje;

(3) A etapa da "revolução científica" (I450-1700): em meados do século XV, a invenção dos tipos móveis de Gutenberg transformou o sistema de produção de livros e revolucionou todo o processo de armazenamento, disseminação e recuperação de informação. $O$ surgimento de um público leitor com a criação de universidades na Idade Média contribuiu para o desenvolvimento de um comércio de cópias manuscritas. A autoria dessas obras nem sempre foi conhecida, pois alguns autores sofreram punições por expressarem livremente seus pensamentos. Ao longo da história, as novas tecnologias intelectuais sempre contribuíram para a ampliação do acesso à informação, processo cujo último marco ocorreu no século XV, com a tipografia de Gutenberg, conforme supramencionado;

(4) Séculos XVIII, (5) XIX e (6) XX: até o final do século XVII, as cartas eram o meio mais utilizado para comunicar os resultados das pesquisas. Cientistas como Bacon, Copernicus, Galileo e Kepler usaram esse meio de comunicação para estabelecer a troca de 
informações. Os cientistas atuaram de forma isolada, sem apoio institucional e de forma amadora. Após esse período, surgiram as primeiras iniciativas de trabalho coletivo, principalmente após a criação de academias decisivas para o surgimento da ciência organizada, permitindo sua estruturação para a criação de programas de desenvolvimento e formação para a pesquisa (Le Codiac, 2004).

\section{I) Ética}

A Ética, como campo de estudo filosófico, no que lhe diz respeito, tem múltiplos aspectos a explorar, aplicados a diferentes dilemas humanos. Na busca da Ética hegeliana, refletindo sobre as subjetividades da moral e buscando a realização do bem, com o apoio de instituições que a garantem - aqui representadas pela própria comunidade científica temos muitos desafios na prática da pesquisa, sendo importante abordar e discutir os possíveis problemas éticos enfrentados (Rios, 2008).

Segundo Schramm (200o), a palavra ethos deu origem aos termos latinos mos, moris, que são traduzidos como moral.

Como nos ensina Lima Vaz (2002), “a Ética assenta no pressuposto de uma racionalidade imanente ao ethos e a sua tarefa como disciplina filosófica consiste essencialmente em explicitar as razões do ethos ou elucidar a inteligibilidade da práxis ética nas suas várias dimensões e Estado".

Para a maioria dos autores, Aristóteles teria sido o primeiro autor a desenvolver o pensamento sobre a Ética. Tal pensamento teria surgido da reflexão sobre a diferença entre conhecimento teórico e conhecimento prático e no entendimento de que o conhecimento relacionado às coisas humanas não seria passível de demonstração teórica como ocorre na matemática e na física, e que sujeitar as ações humanas a leis tão precisas, quanto à ciência, seria inviável, segundo Silva, Segre e Selli, 2007.

No entanto, segundo Cherri (2014), foi no início da Modernidade, no século XVII, que Descartes propôs a razão como uma teoria do conhecimento humano, ou seja, uma ordem mecanicista racional, sem a intervenção dos sentidos, cuja base estava na metafísica. Procurou construir um sistema harmonioso em que a razão, exercida no campo das ideias, fosse a única responsável pela verificação da verdade e capaz de conhecer a realidade. 

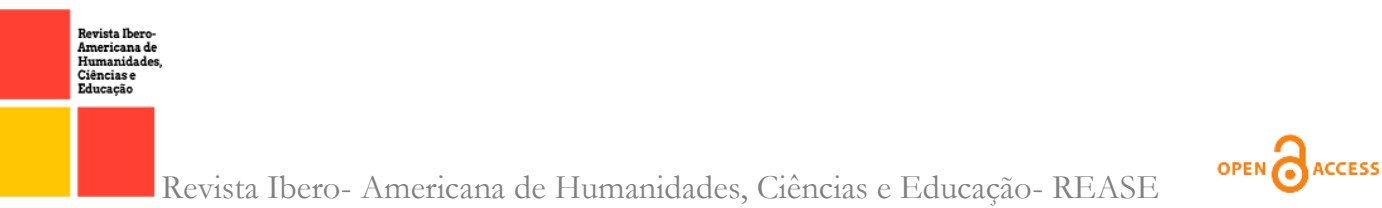

Ainda, de acordo com o autor, o pensamento cartesiano foi refutado por Kant, que, influenciado por Hume, um empirista cético, foi forçado a adotar uma postura crítica diante da estreita correlação entre conhecimento e realidade declarada pelo racionalismo, criticando a metafísica. Kant procurou dar um fundamento sólido à convicção de que existe uma ordem superior no campo transcendental capaz de satisfazer as demandas morais do ser humano. Tal fundamento estaria no direito ético, autônomo e independente, imune às críticas do restrito campo da ciência. A Ética, na visão kantiana, não precisa de dados sobre sensibilidade, e essa "consciência moral" é tão evidente quanto à ciência de Newton. É a razão aplicada à prática humana (Cherri, 2014).

Para Schramm (2015), pode-se dizer que com o avanço da ciência, e com o aprimoramento das técnicas, prevaleceu o caráter experimental da razão e do conhecimento, e com isso predominou a perda de clareza da diferença entre teoria e prática, onde preponderou a ação humana. Passou a depender cada vez mais do conhecimento e de sua tecnologia, portanto, se antes a ética dependia de uma configuração específica do conhecimento prático entendido como discernimento, passou a simbolizar um derivado tecnológico da ciência, em que a racionalidade se tornou exclusivamente técnica onde a ação humana não não mais se dedique ao discernimento entre o bem e o mal, justo ou injusto, correto ou incorreto, mas a uma gestão técnica baseada em parâmetros científicos.

Porém, de acordo com Lopes (2014), que devido às inúmeras atrocidades praticadas em nome da ciência nos campos de concentração nazistas na época da Segunda Guerra Mundial, com cobaias humanas por médicos e cientistas, surgem manifestações com o objetivo de resgatar os parâmetros éticos que devem ser observados nas práticas científicas. Em seguida, é formulado o Código de Nuremberg, o primeiro documento ético internacional que contém preceitos disciplinares para as atividades científicas que exige de seus operadores: o livre consentimento do sujeito na pesquisa, redução de riscos e inconvenientes, possibilidade de revogação da autorização por parte de o assunto, proporcionalidade entre riscos e benefícios, pesquisa prévia obrigatória em animais, etc.

Ainda segundo esse mesmo autor, tais preceitos buscaram resgatar alguns referentes mínimos para a ação ética, marcando, portanto, o nascimento da primeira norma da ética aplicada, e também o renascimento de um movimento, que hoje se denomina Bioética, mas 
que, na prática, sempre existiu como uma Ética aplicada à vida. Porém, antes de compreender os processos éticos de CC como o produto final da pesquisa desejada, é necessário entender a Ética durante a fase de pesquisa (Lopes, 2014).

\section{2) Ética em Pesquisa}

Não se pode negar que a pesquisa científica traz, a cada dia, muitas descobertas de aprimoramento para a melhoria da vida humana, e quando se trata de pesquisa com seres humanos, a ética é fundamental.

Ao longo dos séculos (especialmente no século XX), experimentos foram conduzidos em seres humanos com diferentes padrões de qualidade e Ética. A história relata vários exemplos do uso de seres humanos em estudos e pesquisas que chocaram e ainda chocam a humanidade. Nestes casos, a ausência de mecanismos de controle baseados em critérios éticos e morais resultou no abuso de experimentos e na "cobaização" do ser humano (Hossne, Vieira, 1995).

A Bioética, conforme mencionada, e como se conhece hoje, nasceu nos Estados

Unidos entre o final dos anos 196o e o início dos anos 1970, quando uma série de fatores históricos e culturais chamaram a atenção para a Ética aplicada. O termo "bioética" é um neologismo inventado pelo oncologista van Rensselaer Potter, em 1970, e difundido graças ao seu livro 'Bioética: uma ponte para o futuro em 197I' (Mori, 1994).

Para Araújo (2003), o princípio da autonomia deve ser considerado no desenvolvimento de experimentos com seres humanos, por meio da obtenção do consentimento livre e esclarecido do sujeito, objeto da pesquisa. Representa um dos pilares éticos na execução desse tipo de pesquisa: o consentimento é o livre exercício da autonomia do voluntário. Sua gênese está ligada à uma análise criteriosa entre riscos e benefícios, sendo a maximização dos benefícios o caminho ideal para o desenvolvimento de pesquisas com seres humanos. É possível prever os danos de um experimento por meio de pesquisas anteriores: com animais (em laboratório - embora esse seja um assunto controverso e que demanda grande diálogo), in vitro e, até mesmo, por meio de simulações em computador.

Esse material pode ser obtido por meio de um cuidadoso estudo bibliográfico. E, dessa forma, é respeitado o princípio da não maleficência, que é representado na pesquisa 
com seres humanos pela garantia de que danos previsíveis serão evitados. A relevância social da pesquisa envolvendo seres humanos e sua contribuição para o voluntariado e a sociedade simbolizam o princípio da justiça. $\mathrm{O}$ conceito de equidade, que pertence ao cerne do princípio da justiça, deve ser abordado minimizando a carga sobre os sujeitos vulneráveis. Os princípios da Bioética devem ser considerados na execução de todas as pesquisas envolvendo seres humanos. É dessa forma que garantirá à sociedade que essas experiências levem em conta a dignidade do ser humano (Lopes, 2014).

A coleta de dados é intrínseca ao se fazer ciência, pois é a partir dos dados coletados, organizados e analisados, que a ciência se desenvolve. Davis e Vickery (2007) (apud Schiessl \& Moreno, 2019), afirmam que os dados primários se tornaram a principal moeda da ciência. A Organização para Cooperação e Desenvolvimento Econômico (OCDE) define dados de pesquisa como "registros factuais [...] usados como fontes primárias para pesquisa científica e que são comumente aceitos na comunidade científica como necessários para validar os resultados da pesquisa" (OCDE, 2007).

No que diz respeito à proteção dos participantes da pesquisa científica, algumas medidas já existem há muitos anos, como o direito de desistência (deixar de participar da pesquisa a qualquer momento) e a avaliação da proposta de pesquisa por um comitê competente (no Brasil, um parecer ético de um comitê de pesquisa), antes do início da investigação. No entanto, essas medidas foram concebidas para proteger as pessoas que participam da pesquisa de danos físicos, e não são suficientes em um contexto científico globalizado, em que o fluxo de dados circula internacionalmente por meio de colaboração científica (Kaye, 2012). Portanto, se o fluxo de dados dos processos de colaboração científica permite o compartilhamento e a reutilização de dados de pesquisa, a aprovação de um projeto de pesquisa por um comitê pode ser questionada. Afinal, a avaliação considerou o método, as políticas de gerenciamento de dados e os limites da pesquisa para um objetivo específico, em um determinado momento, elaborado por um pesquisador (ou grupo) previamente definido. A partir do momento em que os dados são disponibilizados para novos projetos, esses limites são extrapolados e os dados utilizados para outros fins, sob a égide de novas perspetivas, podendo mesmo ser cruzados com outros conjuntos de dados de fontes heterogéneas. 
Segundo Shinkai (20II), mesmo o Termo de Consentimento Livre e Esclarecido, cujo objetivo é dar ao participante autonomia para tomar decisões sobre os riscos que a pesquisa oferece à sua privacidade, não é capaz de informar os possíveis usos subsequentes dos dados, simplesmente porque os princípios da ciência aberta repousam, justamente, na livre (e, portanto, imprevisível) troca dessas informações, uma vez que considera o conhecimento científico um bem da Humanidade. Portanto, os atuais mecanismos para garantir a proteção da privacidade das pessoas que participam de pesquisas científicas são insuficientes. É preciso discutir e pensar soluções que garantam a devida privacidade dos participantes, mas que, ao mesmo tempo, não impeçam o avanço da ciência e evitem a colaboração científica.

Uma técnica para garantir a privacidade dos participantes em um conjunto de dados é o anonimato. Esse processo consiste em ocultar (ou embaralhar, ou substituir) o nome do participante da pesquisa, mantendo disponíveis os demais dados relativos às pessoas. No entanto, Mayer-Schonberger e Cukier (2013) alertam que o anonimato funciona em um pequeno universo de dados. Segundo os autores, com o aumento da quantidade e variedade de informações, fica mais fácil reidentificar os participantes. Infere-se, portanto, que não basta mais ocultar nomes ou dados como datas de nascimento, filiação ou outros, devido à triangulação que se torna possível a partir do uso secundário e terciário de dados de pesquisa (cruzando-os com outras bases de dados para gerar novas informações).

Uma pesquisa das opiniões das partes interessadas sobre a pesquisa de Saúde Pública de compartilhamento de dados no Quênia destaca que as preocupações com a privacidade são importantes, pois sua perda cria riscos de estigma e desrespeito quando associada a dados confidenciais. Essas informações podem incluir dados clínicos, diagnósticos individuais de HIV, dados genéticos e de comportamento sexual (Jao et al., 2015). Além da perda de privacidade e possível estigmatização, outros desafios apontados na pesquisa são o impacto sobre a autonomia e a concorrência desleal, inclusive por meio do "mau uso" (intencional ou não) dos dados. 


\section{3) Ética na publicação dos resultados: a própria comunicação científica}

A CC traz consigo muitas questões relacionadas à Ética. Marcovitch et al. (2010) relatam plágio, publicação duplicada, alterações não divulgadas nos protocolos antes da investigação ou comportamento ético questionável. Esse espectro, que vai do "erro honesto", ou seja, sem intenção de fraude, à fraude total, é representado por uma série de erros científicos. Por um lado, deste espectro temos aqueles que estão próximos de um erro inadvertido e que são difíceis de detectar, como observação ou análise incorreta, arquivamento impróprio, dobrar e cortar postes, e até mesmo ignorar o trabalho anterior de terceiros. A produtividade acadêmica é uma exigência dos órgãos reguladores da pósgraduação no país e das agências de fomento, e talvez por isso os autores se preocupem principalmente com a prevenção de erros no processo de publicação, “[...] casos de plágio, fraude, falsificação de dados, duplicação e segmentação de resultados, autoria indevida, conflito de interesses, etc" (Shinkai, 20II). Especificaremos esses [e alguns outros] tópicos abaixo.

\section{A) PLÁGIO}

Plágio pode ser definido como "apropriação ou imitação da linguagem, ideias ou pensamentos de outro autor, e representá-los como se fosse ele quem os estivesse usando". Embora essa prática não deva estar presente no meio acadêmico, hoje e no mundo, o fato se repete e tem sido amplamente divulgado na mídia (Veras, 2013).

A falta de Ética na pesquisa científica traz sérias complicações à comunidade científica para novos trabalhos, o que por sua vez levará a outros: uma fonte mal avaliada torna-se uma cadeia de trabalhos produzidos com informações errôneas. Além disso, como mencionado pelos autores acima, revela uma desonestidade intelectual de quem escreveu e ganhou apoio para a pesquisa original. Os tipos de plágio são: direto, indireto, consentido, de fontes (ou de origem) e autoplágio, conforme Krokoscz (2012).

I. Plágio direto: quando se realiza cópia literal de texto original;

2. Plágio indireto: quando o escritor faz uma paráfrase, ou seja, apresenta informações de um documento consultado com suas próprias palavras, mas não cita, indica ou identifica (faz referência) a obra original; 
3. Plágio por consentimento: quando há situações que envolvem conluio, em outras palavras, quando há combinação de duas ou mais pessoas com o objetivo de obter algum tipo vantagem em alguma situação;

4. Plágio de fontes (ou de origem): quando ocorrem citações imprecisas - isso pode acontecer deliberadamente quando o escritor usa as fontes do autor consultado como se ele próprio as tivesse consultado, em primeira mão;

5. Autoplágio: quando há casos de trabalhos acadêmicos do mesmo autor, que já foram submetidos à avaliação em determinada disciplina, curso, revista, entre outros, e são reenviados para atender aos requisitos acadêmicos, ou mesmo obter notas, como se fossem originais.

Praticar plágio, mesmo que inconscientemente, "representa uma desagradável surpresa para o plagiador, uma grave violação ética por parte do plagiador e um grande desconforto para os editores e revisores da revista que dirigiram o plágio" (Albuquerque, 2009). Para Diniz e Munhoz (20II), o crime de plágio é reconhecido quando atinge uma obra protegida por direitos autorais. Os mesmos autores também afirmam que copiar conteúdo pode ter um significado diferente entre literatura e ciência.

$\mathrm{Na}$ Literatura, é comum a readaptação criativa de uma obra, enquanto na Ciência deve ser registrada a fonte de autoria das ideias (Diniz, 2008). Em relação à Lei de Propriedade Intelectual, não há menção sobre o plágio, mas se proíbe a cópia não autorizada de uma obra intelectual (Diniz; Munhoz, 20II). Embora o plágio não seja mencionado nas leis de direitos autorais, Narchi e Secaf (2002) relatam que, por exemplo, os Códigos de Ética Médica proíbem os profissionais da área de fazer cópias sem citar a fonte.

$\mathrm{O}$ autor comete plágio quando deixa de usar aspas duplas em uma frase copiada diretamente de outro texto ou quando usa indiretamente as ideias de outro autor sem citálo corretamente (Albuquerque, 2009). O revisor de artigos científicos também comete plágio, quando atrasa a avaliação para incorporar o conteúdo dos artigos que avalia em suas publicações (Rodrigues; Crespo Miranda, 2006) ou quando utiliza o conteúdo sem autorização ou sem citar, atrasando ou não o opinião. Em qualquer situação deve-se ter muito cuidado, pois qualquer erro cometido em relação ao uso das ideias de outros autores pode se tornar um caso de plágio. 


\section{B) SALAMI SLACING}

Inicialmente, define-se os termos conhecidos como publicação em salame, salame slicing ou salciping, em inglês, termos que são encontrados na Literatura Científica. 'O corte de salame' se trata de uma prática de publicação utilizada por pesquisadores da ciência como forma de publicação de dados de pesquisa. Esse modo de publicação foi definido por Smolčić (2013) como a publicação de dois ou mais artigos derivados de um único estudo. Por exemplo, os dados coletados em um único estudo são divididos em vários segmentos e publicados em diferentes artigos, cujo tamanho só é grande o suficiente para obter resultados e conclusões razoáveis, também conhecida como "unidade editável mínima".

No entanto, a publicação em salame ainda é considerado um problema de má conduta. Em outras palavras, não é ético "dividir" os resultados de uma mesma pesquisa em vários artigos, desnecessariamente, apenas para mascarar a produtividade, tornando-a uma forma redundante de publicação que secretamente aumenta o número de artigos científicos de um autor. Essa prática pode gerar imensos benefícios para os autores, como o avanço na carreira acadêmica ou a obtenção de financiamento para projetos de pesquisa. Editorial Elsevier (2015) considera que uma publicação cortada (ou em salame) se torna um problema ao segmentar um grande estudo em duas ou mais publicações. Esses segmentos são chamados de "fatias" de um estudo que compartilham as mesmas premissas, população e métodos e, portanto, são considerados uma prática inaceitável, pois a mesma "fatia" nunca deve ser publicada mais de uma vez.

Os editores de periódicos científicos reconhecem a dificuldade de detectar uma publicação em salame, uma vez que não existe um software ou algoritmo criado para identificar esse tipo de publicação. A constatação dessa prática é complexa, pois as publicações em salame geralmente não incluem plágio textual. Editores e revisores podem suspeitar de uma postagem de salame. Embora não haja maneiras objetivas de detectar esse tipo de publicação redundante, os artigos suspeitos geralmente relatam tamanho, hipóteses, metodologia e resultados de pesquisa idênticos ou semelhantes e, muitas vezes, incluem os mesmos autores (Smolčić, 2013). 


\section{C) AUTORIA}

Segundo Wasserman 2010, ser autor de um artigo científico significa participar do desenvolvimento de seu conteúdo. Para Rodrigues, Crespo e Miranda (2006), existem três tipos de definições sobre participação em um trabalho científico: autoria, coautoria e colaboração. A autoria pertence ao criador da obra e detém os direitos sobre esta, a coautoria é uma obra conjunta, onde todos os autores têm o mesmo nível de participação, e a colaboração é um trabalho em grupo onde os demais participantes auxiliam o autor principal em diversos setores do trabalho (Rodrigues, Crespo, Miranda, 2006; Wasserman, 2010). Para Vanz e Stumpf (2010), a coautoria em um trabalho científico está diretamente relacionada ao nível de colaboração científica realizada por cada coautor do trabalho, o que nem sempre indica a real colaboração dos colaboradores do artigo. Em relação à autoria, Wasserman (2010) afirma que ela não pode ser vendida ou cedida a terceiros, o que não acontece com os direitos autorais sobre a obra, que pode ser vendida a uma empresa ou editora.

Hoje, há maior importância para o trabalho realizado em coautoria, pois implica a participação de diversos autores, institutos e instituições em um mesmo artigo científico, o que facilita a troca de experiências por novas soluções (Garcia et al., 2010) . Também há coautoria entre países, o que permite maior visibilidade da ciência produzida em países emergentes (Leite, 2008). A coautoria de um artigo científico também envolve aspectos éticos.

Em um artigo científico, as questões éticas também estão relacionadas à ordem em que os nomes dos autores são colocados. Segundo Wasserman (2010), essa ordem depende do consenso entre os grupos de trabalho, uma vez que existem grupos que utilizam a ordem alfabética dos sobrenomes, outros que colocam o nome do autor mais importante em primeiro ou segundo plano, ou mesmo aquelas que colocam em primeiro plano o nome de quem escreveu a peça. Ainda para Wasserman (2010), quando há consenso entre os coautores, não falta Ética. O desejo de ter o nome em primeiro plano ocorre quando a importância da pesquisa tem maior impacto na sociedade (Petroianu, 2002).

A falta de critérios para ordenação de nomes pode causar interferências para a obtenção de vantagens pessoais, como é o caso de um pesquisador que pouco exigiu que 
seu nome fosse o primeiro da lista (Petroianu, 2002). Para García et al. (2010), deve-se ter cuidado para que a coautoria não se transforme em recurso para aumentar o número de publicações de pesquisadores, uma vez que muitos desses pesquisadores têm seu nome incluído em artigo científico devido ao prestígio no meio acadêmico e não ao participação em seu conteúdo.

Os mesmos autores citam critérios impostos pelo International Committee of Medical Journal Editors, que o pesquisador considera merecedores de crédito para: quem contribuiu para a aquisição e interpretação dos dados; redigiu e revisou o conteúdo e participou da aprovação final. Esses critérios não são obrigatórios, por isso, muitas vezes, não são seguidos (Garcia et al., 2010).

Segundo Grieger (2007), Ghostwriting é um tipo de má conduta que pode ser caracterizada tanto como plágio (Spinak, 2014) quanto manipulação de autoria. Grieger também corrobora ao apontar para diferentes tipos de escrita fantasma: autoria 'de presente', 'autoria fantasma' e venda de trabalhos científicos pela internet.

$\mathrm{Na}$ autoria "de presente", por exemplo, os redatores médicos contratados pela indústria farmacêutica produzem os textos que, a seguir, são assinados pelos principais pesquisadores. A prática é comum na área biomédica para mascarar conflitos de interesse com a indústria farmacêutica, o que a princípio já caracteriza condutas antiéticas de todos os envolvidos. $\mathrm{Na}$ 'autoria fantasma' simples, um autor escreve a obra e seu nome não está entre os autores. Este caso é caracterizado principalmente pela ampla comercialização dos chamados artigos científicos, encomendados pela internet, e tem sido considerado um grave problema em vários países.

Independentemente da falta de critérios, o importante é que o grupo atue de acordo com o que for mais justo para seus integrantes. Isso deve ocorrer desde a escolha pela execução das tarefas até a atribuição da autoria.

\section{D) FALSIFICAÇÃO}

Falsificação ou apresentação de dados, procedimentos ou resultados de pesquisas de forma relevante modificada, imprecisa ou incompleta, a ponto de poder interferir na 
avaliação do peso científico que realmente conferem às conclusões deles extraídas (Fapesp, 2014).

\section{E) CONFLITO DE INTERESSES}

Conflito de interesses pode ser definido como um choque entre interesses pessoais e as obrigações primárias de um indivíduo em posição de confiança ou, mais especificamente, como um conjunto de condições que fazem um julgamento profissional em relação a um interesse primordial, como o bem-estar do paciente. ou a validade de uma investigação, tende a ser indevidamente afetada por um interesse secundário, como um ganho econômico (Thompson, 1993). Pode haver conflito de interesses diretamente com o indivíduo que exerce determinada atividade, bem como com pessoas com quem esse indivíduo compartilha um ganho econômico (cônjuge ou dependente, por exemplo), conforme Holmes (2004) (apud Alves \& Tupino , 2007).

Entende-se por conflito de interesses a condição em que a conduta profissional pode ser influenciada por um interesse externo que geralmente (embora não necessariamente) se traduz em ganho financeiro, em detrimento da prática ética da Medicina.

\section{CONCLUSÃO}

A ciência aberta traz uma série de possibilidades sem precedentes na História e pode garantir o melhor aproveitamento dos investimentos realizados em pesquisa, uma distribuição mais equitativa do conhecimento gerado e a aceleração da divulgação da informação nas diferentes áreas da sociedade. Porém, a observação das questões éticas, desde a execução da pesquisa, são de fundamental importância para que, no momento oportuno, os autores tecam um texto de apresentação dos dados que também seja ético. Ainda assim, identifica a necessidade de pesquisadores discutirem esta e outras questões éticas e, em particular, uma oportunidade para cientistas da informação.

Chamamos a atenção para o sentido geral da ética que exige importantes discussões e reflexões, como ramo específico da Filosofia, e que é possível aplicá-la a diferentes setores da atividade humana, incluindo a atividade de infocomunicação, bem 
como a atividade científica e de investigação. Efetivar CC é uma obrigação da vida contemporânea, pois é possível avançar nas áreas da Saúde e outras áreas, permitindo que as ciências ofereçam sempre o que há de melhor e mais adequado em diferentes contextos.

\section{REFERÊNCIAS}

ABBAGNANO, N. Dicionário de Filosofia (5. ed.). São Paulo: Martins Fontes, 2007.

ALVES, E.M.O.; TUBINO, P. Conflito de Interesses em Pesquisa Clínica. Acta Cirurgica Brasileira, 22, 2007.

ARAÚJO, L.Z.S. Aspectos éticos da pesquisa científica. Pesquisa Odontologica Brasileira, 17, 57-63, 2003.

CHERRI, C.G.M. O papel da dúvida na filosofia cartesiana: a interpretação hegeliana sobre Descartes nas Lições sobre História da Filosofia. Anais do seminário dos estudantes de pós-graduação em filosofia da UFSCar, 2014.

GOMES, C. M. Comunicação Científica: Alicerces, transformações e tendências. Livros, LabCom, 2013.

HOSSNE, W. S. \& Vieira, S. Experimentação com seres humanos: aspectos éticos. In: Segre M, Co hen C (org.) Bioética. São Paulo, EDUSP, I27-I46, 1995.

JAO, I; KOMBE, F; MWALUKORE, S; BULL, S; PARKER, M; KAMUYA, D; MARSH, V. Research stakeholders' views on benefits and challenges for public health research data sharing in Kenya: The importance of trust and social relations. PLOS ONE, Io(9), eo135545. DOI:10.1371/journal.pone.0135545, 2015.

KAYE, J. The tension between data sharing and the protection of privacy in genomics research. Annual Review of Genomics and Human Genetics, 13, 415-431, 2012.

LE GOFF, J. Os intelectuais na Idade Média. Rio de Janeiro: José Olympio, 2003.

LE COADIC, Y.F. A Ciência da Informação. 2. Brasília: Briquet de Lemos, 2004.

LIMA VAZ, H. C. Ética e educação. Escritos de filosofia VII: raízes da modernidade. São Paulo: Loyola, 2002.

LOPES, J. A. (2014). Bioética - uma breve história: de Nuremberg (1947) a Belmont (1979). Revista Médica de Minas Gerais, 24, 262-273, 2014. 
MARCOVITCH, H; BARBOUR, V; BORRELL, C; BOSCH, F; FERNÁNDEZ, E; MACDONALD, H; NYLENNA, M. Conflict of interest in science communication: More than a financial issue. Croatian Medical Journal, 5I(I), 7-15, 2010.

MAYER-SCHONBERGER, V. \& CUKIER, K. Riscos. In: V. Mayer-Schonberger \& K. Cukier, Big Data: Como extrair volume, variedade, velocidade e valor da avalanche de informação cotidiana. Rio de Janeiro: Elsevier,I05-II8, 2013.

MEADOWS, A. J. A comunicação científica. Brasília: Briquet de Lemos/Livros, 1999.

MORI, M. A. Bioética: sua natureza e história. Humanidades 9, 332-34I, 1994.

OECD (Organization for Economic Co-Operation and Developement). Principles and guidelines for access to research data from public funding. Danvers: OECD, 2007.

RIOS, T. A. A presença da filosofia e da ética no contexto profissional. São Paulo: Organicom, 8, 79-88, 2008.

SCHAUDER, D. Electronic publishing of Professional articles: attitudes of academics and implications for the scholarly communication industry. Journal of the American Society for Information Science, v. 45, 2, 73-100, 1994.

SCHIESSL, I.T. \& MORENO, F.P. A relação entre os conjuntos de dados de pesquisa depositados em repositório de dados e os periódicos científicos. Pesq. Bras. em Ci. da Inf. e Bib., João Pessoa, v. 14, n. 4, p. o66-o77, 2019.

SCHRAMM, F.R. \& KOTTOW, M. Nuevos desafios para los Comités de Bioética en investigación. Cuadernos Médico Sociales 41,19-26, 2000.

SCHRAMM, F. R. Três ensaios de bioética. Rio de Janeiro : Editora FIOCRUZ, 2015.

SHINKAI, R.S. Integridade na pesquisa e ética na publicação. Scientia Medica, vol., 2I, I, 20II.

SILVA F. L.; SEGRE M.; SELLI L. Da ética profissional para a bioética. In ANJOS, M. F., \& SIQUEIRA, J. E. (Orgs.), Bioética no Brasil: tendências e perspectivas. 57-67. Aparecida: Ideias \& Letras; São Paulo: Sociedade Brasileira de Bioética, 2007.

SMOLČIĆ, V. S. Salami publication: Definitions and examples. Biochemia Medica, 23(3), 237-24I, 2013.

THOMPSON, D.F. Understanding financial conflicts of interest. $\mathrm{N}$ Engl J Med. 1993;329:573-6, 1993. 
VERAS, R. Plagiarism in scientific communication: the need to combat. Rev. Bras. Geriatr. Gerontol. Rio de Janeiro, 16(I),5-6, 2013.

VICKERY, B.C. Scientific Communication in history. London: The Scarecrow Press, 2000. 